\title{
An Extended Consistent Fuzzy Preference Relation to Evaluating Website Usability
}

\author{
Tenia Wahyuningrum ${ }^{1}$, Azhari Azhari*2 ${ }^{2}$, Suprapto ${ }^{3}$ \\ Department of Informatics, Institut Teknologi Telkom Purwokerto, Indonesia ${ }^{1}$ \\ Department of Computer Science and Electronics, Universitas Gadjah Mada Yogyakarta, Indonesia, ${ }^{1,2,3}$
}

\begin{abstract}
In the current era, website developers recognize usability evaluation as a significant factor in the quality and success of e-commerce websites. Fuzzy Analytical Hierarchy Process (FAHP) is one method to measure the usability of the website. Several researchers have applied Logarithmic Fuzzy Preference Programming (LFPP) approach to deriving crisp weight from fuzzy pairwise comparison matrix of FAHP approach. However, there is a lack of LFPP method in determining the consistency index of the decision-maker judgment. In some cases, LFPP method will produce a consistency value of 0 from consistent fuzzy comparison matrices. This value indicates there is a contradiction with what the previous researchers have said, that a constant matrix value should be more than 0 . This research proposes the extended Consistent Fuzzy Preference Relation (ECFPR) to assist the regular judgment for specifying the weights in measuring ecommerce website usability. The CFPR method used to form a new pairwise comparison matrix. ECFPR was calculating the lower and upper values at the fuzzy triangular number from the only $n-1$ comparison, where $n$ is the number of criteria. The numerical experiment showed that the consistency index obtained by extended CFPR method was more significantly better than LFPP method. It was revealed that the optimal value always more than 0 . The consistency index of ECFPR method has a higher mean value than LFPP, so that the use of the ECFPR method can improve the amount of consistency comparison matrices. The ECFPR method was also successfully implemented with the experimental case on evaluating ecommerce website usability.
\end{abstract}

Keywords-Usability; e-commerce; website quality; logarithmic fuzzy preference programming; consistent fuzzy preference relations

\section{INTRODUCTION}

Current usability measurement methods do not yet have the right uniformity and agreement on standards in software [1], [2]. One measure for websites usability is the sum of products between the weights of the criteria and the value of each of the criteria [3]-[5]. Researchers often regard the weighting of standards as a multi-criteria decision-making problem, given its complex structure. They usually break down the complex issues into its elements in a hierarchy. Several researchers have conducted usability measurements using a combination of fuzzy numbers and Analytical Hierarchy Process (FAHP) [6][9]. Fuzzy numbers consider the uncertainty and doubt factors in the experts in determining the level of importance between criteria. Fuzzy logic and fuzzy decision making are part of the branch of fuzzy theory. In fuzzy decision making consider

*Corresponding author: arisn@ugm.ac.id. This research was supported by the Ph.D grant of the Indonesia endowment fund for education (LPDP) ministry of Finance Republik Indonesia for Tenia Wahyuningrum (No. PRJ-4811/LPDP.3/2016). optimizing problems with certain limitations while fuzzy logic is the basis of knowledge in fuzzy systems and controls [10].

Logarithmic Fuzzy Preference Programming (LFPP) is one method to evaluate usability based on FAHP method [11]. LFPP is an approach using non-linear programming to derive the weight of criteria. LFPP uses the logarithm of natural numbers to repairing Fuzzy Preference Programming (FPP) approach that caused the negative of fuzzy membership degree [12], [13]. However, the LFPP method has its drawbacks; in some cases, a pairwise comparison matrix that consistently produces a value of 0 [14], [15]. This case is not in line with the definition that states that the more consistent fuzzy pairing comparison matrix, the optimal value $\left(\lambda^{*}\right)$ is closer to 1 [16]. There is a presumption that the probability of a value of 0 in $\lambda^{*}$ is due to a matrix that is not consistent. Therefore, before calculating the weights using the LFPP method, it is necessary to ensure the consistency of the model. The technique for guaranteeing a matrix to be consistent is called Consistent Fuzzy Preference Relation (CFPR). CFPR is an approach to reduce the number of comparisons that are often done by users in determining preferences between criteria or alternatives. The weakness of CFPR only considers the modal value at triangular fuzzy number so that it produces a comparison matrix with crisp numbers. The extended CFPR is reviewing the upper and lower bound and creating a comparison matrix in pairs with fuzzy triangular numbers. By applying the extended CFPR method, it is expected to increase fuzzy preference relationships consistency provided by experts to make it better. The extended CFPR based on user judgment is expected to be valid and consistent so that it can give good weight also from each usability criteria.

The organization of this paper is as follows. Section 2 briefly reviews the LFPP and illustrates its consistency equal to 0 . Section 3 proposes the extended CFPR to create the fuzzy pairwise comparison matrix. Section 4 explained the numerical case of usability evaluation method using extended CFPR and LFPP. The paper concludes in Section 5.

\section{LITERATURE REVIEW}

\section{A. Logarithmic Fuzzy Preference Programming}

Wang and Chin (2011) reforming the Fuzzy Preference Programming (FPP) weight derivation. They modified the FPP method by adding natural logarithms function to improve the negative membership degree and arising in multiple optimal solutions. Negative value to makes the expected solution less 
valid [16]-[19]. The fuzzy pairwise comparison matrix from expert judgment can be expressed as

$A=\left(a_{i j}\right)_{n \times n}$

$A=\left(\begin{array}{ccc}(1,1,1) & \ldots & \left(l_{1 n}, m_{1 n}, u_{1 n}\right) \\ \left(l_{21}, m_{21}, u_{21}\right) & (1,1,1) & \left(l_{2 n}, m_{2 n}, u_{2 n}\right) \\ \vdots & \vdots & \vdots \\ \left(l_{n 1}, m_{n 1}, u_{n 1}\right) & \ldots & (1,1,1)\end{array}\right)$

where $n$ is the number of criteria, $l_{i j}=1 / u_{j i}, m_{i j}=1 / m_{j i}, u_{i j}$ $=1 / l_{j i}$ and $0<l_{i j}<m_{i j}<u_{i j}$ for all $i, j=1,2, \ldots, n, j \neq i$. To find a crisp priority vector $W=\left(w_{1}, w_{2}, \ldots, w_{n}\right)^{T}>0$ with $\sum_{i=1}^{n} w_{i}=1$ for the fuzzy pairwise comparison matrix [16]. The approximate equation uses natural logarithmic numbers for the improvement of fuzzy pairwise matrix (1).

The LFPP method formulated as Minimize

$J=(1-\lambda)^{2}+M \cdot \sum_{i=1}^{n-1} \sum_{j=i+1}^{n}\left(\delta_{i j}^{2}+\eta_{i j}^{2}\right)$

Subject to

$\left\{\begin{array}{l}x_{i}-x_{j}-\lambda \ln \left(\frac{m_{i j}}{l_{i j}}\right)+\delta_{i j} \geq \ln l_{i j}, i=1,2, \ldots, n-1, j=i+1, \ldots, n, \\ -x_{i}+x_{j}-\lambda \ln \left(\frac{u_{i j}}{m_{i j}}\right)+\eta_{i j} \geq-\ln u_{i j}, i=1,2, \ldots, n-1 ; j=i+1, \ldots, n, \\ \lambda, x_{i} \geq 0, i=1,2, \ldots, n, \\ \delta_{i j}, \eta_{i j} \geq 0, i=1,2, \ldots, n-1 ; j=i+1, \ldots, n,\end{array}\right.$

where $x_{i}=\ln w_{i}$ for $i=1,2, \ldots, n$ and $M$ is a specified large number such as $M=10^{3}$. Equation (3) can be used to calculate the weight of each criterion :

$w_{i}^{*}=\frac{\exp \left(x_{i}^{*}\right)}{\sum_{j=1}^{n} \exp \left(x_{j}^{*}\right)}, i=1,2, \ldots, n$,

where $\exp ()$ is the exponential function $\exp \left(x_{i}^{*}\right)=e^{x_{i}^{*}}$ for $i$ $=1,2, \ldots, n$.

\section{B. Consistent Fuzzy Preference Relation}

Preference relations are usually constructed as a matrix that represents the degree of interest for the first criteria over the second criteria. The relationship of this assessment can be multiplicative preference relations of fuzzy preference relations. Multiplicative preference relations can be formulated as

$R \subseteq A \times A, R=\left(r_{i j}\right), \forall i, j \in\{1,2, \ldots, n\}$,

where $A$ is the set of criteria or alternatives, $r_{i j}$ is the preference ratio of criteria or alternative $a_{i}$ to $a_{j}, a_{i j} \cdot a_{j i}=1, \forall i, j$ $\in\{1,2, \ldots, n\}$. Furthermore, the relationship will be represented by a pairwise matrix comparison $P=p_{i j}$, where the size is $n \times n, p_{i j}=\mu_{p}\left(a_{i}, a_{j}\right), \forall i, j \in\{1,2, \ldots, n\}$ and the value of the membership function of fuzzy logic. Elements in the pairwise comparison matrix are calculated using several propositions [20].

Proposition 1. Consider set criteria or alternatives, $X=\left\{x_{1}, x_{2}, \ldots, x_{n}\right\}$ associated with a reciprocal multiplicative preference relation $A=\left(a_{i j}\right)$ for $a_{i j} \in[1 / 9$, 9]. Then, the corresponding reciprocal fuzzy preference relation, $\mathrm{P}=\mathrm{p}_{\mathrm{ij}}$ with $\mathrm{p}_{\mathrm{ij}} \in[0,1]$ associated with $\mathrm{A}$ is given as

$p_{i j}=g\left(a_{i j}\right)=\frac{1}{2}\left(1+\log _{9} a_{i j}\right)$

Proposition 2. For each $\mathrm{P}=\mathrm{g}(\mathrm{A})$, where $\mathrm{P}=\left(\mathrm{p}_{\mathrm{ij}}\right)$, the booth of equations (6) and (7) are equivalent.

$p_{i j}+p_{j k}+p_{k i}=\frac{3}{2}, \forall i, j, k$

$p_{i j}+p_{j k}+p_{k i}=\frac{3}{2}, \forall i<j<k$

Proposition 3. For each $\mathrm{P}=\left(\mathrm{p}_{\mathrm{ij}}\right)$, the booth of equations (8) and (9) are equivalent.

$$
\begin{aligned}
& p_{i j}+p_{j k}+p_{k i}=\frac{3}{2}, \forall i<j<k \\
& p_{i(i+1)}+p_{(i+1)(i+2)}+\ldots+p_{(i+k-1)(i+k)}+p_{(i+k) i}=\frac{k+1}{2}, \forall i<j .
\end{aligned}
$$

Proposition 3 is used to construct a consistent fuzzy preference relation from the set of $n-1$ values $\left\{p_{12}, p_{23}, \ldots, p_{n-1 n}\right\}$. A decision matrix with entries that are not in the interval $[0,1]$, but in an interval $[-k, 1+k], k>0$, can be obtained by transforming the result values using a transformation function that preserves reciprocity and additive consistency. It is given by the function $f:[-k, 1+k]$ to $[0,1]$, $f(x)=(x+k) /(1+2 k)$.

\section{PROPOSED METHOD}

\section{A. Extended Consistent Fuzzy Preference Relation}

Wang and Chin (2011) argued that the consistency index of fuzzy pairwise comparison can be seen at the value of $\lambda^{*}$ and $\delta$ [16]. The inconsistency in a fuzzy pairwise comparison matrix could be expressed as a Proposition 4.

Proposition 4. If $\left(\delta^{*}>0\right) \wedge\left(\lambda^{*}=0\right)$ then the matrix is very inconsistent.

Proposition 4 can be broken down into two new schemes $p$ and $q . \quad p=\left(\delta^{*}>0\right) \wedge\left(\lambda^{*}=0\right)$ and $q=$ the matrix is strong inconsistent. The proposition can be explained as $p \rightarrow q$, then the equivalent of Proposition 4 is $\neg q \rightarrow \neg p$. It is also can be expressed as a Proposition 5. 
Proposition 5.

$\neg q \rightarrow \neg\left(\left(\delta^{*}>0\right) \wedge\left(\lambda^{*}=0\right)\right)$

$\neg q \rightarrow \neg\left(\delta^{*}>0\right) \vee \neg\left(\lambda^{*}=0\right)$

$\neg q \rightarrow\left(\delta^{*} \leq 0\right) \vee\left(\lambda^{*} \neq 0\right)=$ true

If $r=\left(\delta^{*} \leq 0\right), s=\left(\lambda^{*} \neq 0\right)$ then $\neg q \rightarrow r \vee s$. Because of the $\delta^{*}=\sum_{i=1}^{n-1} \sum_{j=i+1}^{n}\left(\delta_{i j}^{*^{2}}+\eta_{i j}^{*^{2}}\right)$ is always more than equal to 0 , then the proposition $r$ is always false. For the statement to be true, the $\lambda^{*}$ must be not equal to 0 . It can be said, that the consistency of the fuzzy pairwise matrix must be not equal 0 $\left(\lambda^{*} \neq 0\right)$. The condition of this proposition to comply with the truth table of OR operations.

Experiment 1. Economic factors sub-criteria on shipping registry problem based on Wang and Chin (2011) using LFPP and AHP method used to analyze the consistency index of the fuzzy pairwise comparison matrix [16], [21], [22].

$$
X=\left(\begin{array}{cccc}
(1,1,1) & \left(\frac{2}{3}, 1, \frac{3}{2}\right) & (1,1,1) & \left(\frac{2}{5}, \frac{1}{2}, \frac{2}{3}\right) \\
\left(\frac{2}{3}, 1, \frac{3}{2}\right) & (1,1,1) & \left(\frac{2}{5}, \frac{1}{2}, \frac{2}{3}\right) & \left(\frac{2}{3}, 1, \frac{3}{2}\right) \\
(1,1,1) & \left(\frac{3}{2}, 2, \frac{5}{2}\right) & (1,1,1) & \left(\frac{2}{5}, \frac{1}{2}, \frac{2}{3}\right) \\
\left(\frac{3}{2}, 2, \frac{5}{2}\right) & \left(\frac{2}{3}, 1, \frac{3}{2}\right) & \left(\frac{3}{2}, 2, \frac{5}{2}\right) & (1,1,1)
\end{array}\right)
$$

In the AHP method, the consistency ratio value represents an appropriate pairwise comparison matrix. Suppose $X(l, m, u)$ is a triangular fuzzy number (TFN), then the defuzzified value is computed as (11) [23].

$x_{i j}=(l+4 m+u) / 6$

where $l$ is the lower value, $m$ is the modal value, and $u$ is the upper value of the support of $X$ respectively. Equation (11) can be used to estimate the crisp pairwise comparison matrix $X$.

$$
X=\left(\begin{array}{cccc}
1 & 1.02 & 1 & 0.5 \\
0.97 & 1 & 0.5 & 1.02 \\
1 & 2 & 1 & 0.5 \\
2 & 0.97 & 2 & 1
\end{array}\right)
$$

Using the AHP method, the result of the consistency index (CI) is 0.06 , and the consistency ratio (CR) is 0.07 , which is consistency. The consistency index also calculated using LFPP method for investigating the differences of conclusion between two approaches. For $X$ is a fuzzy pairwise matrix, the calculation can be written as Minimize

$$
J=(1-\lambda)^{2}+M \sum_{i=1}^{3} \sum_{j=i+1}^{4}\left(\delta_{i j}^{2}+\eta_{i j}^{2}\right)
$$

Subject to

$$
\left\{\begin{array}{l}
x_{1}-x_{2}-\lambda \ln (3 / 2)+\delta_{12} \geq \ln (2 / 3), \\
-x_{1}+x_{2}-\lambda \ln (3 / 2)+\eta_{12} \geq-\ln (3 / 2), \\
x_{1}-x_{3}-\lambda \ln (1)+\delta_{13} \geq \ln (1), \\
-x_{1}+x_{3}-\lambda \ln (1)+\eta_{13} \geq-\ln (1), \\
x_{1}-x_{4}-\lambda \ln (5 / 4)+\delta_{14} \geq \ln (2 / 5), \\
-x_{1}+x_{4}-\lambda \ln (4 / 3)+\eta_{14} \geq-\ln (2 / 3), \\
x_{2}-x_{3}-\lambda \ln (5 / 4)+\delta_{23} \geq \ln (2 / 5), \\
-x_{2}+x_{3}-\lambda \ln (4 / 3)+\eta_{23} \geq-\ln (2 / 3), \\
x_{2}-x_{4}-\lambda \ln (3 / 2)+\delta_{24} \geq \ln (2 / 3), \\
-x_{2}+x_{4}-\lambda \ln (5 / 4)+\eta_{24} \geq-\ln (2 / 5), \\
x_{3}-x_{4}-\lambda \ln (5 / 4)+\delta_{34} \geq \ln (2 / 5), \\
-x_{3}+x_{4}-\lambda \ln (4 / 3)+\eta_{34} \geq-\ln (2 / 3), \\
\lambda, x_{1}, x_{2}, x_{3}, x_{4}, \delta_{12}, \delta_{13}, \delta_{14}, \delta_{23}, \delta_{24}, \delta_{34} \geq 0, \\
\eta_{12}, \eta_{13}, \eta_{14}, \eta_{23}, \eta_{24}, \eta_{34} \geq 0 .
\end{array}\right.
$$

Define a sufficiently large number for $M=10^{3}$, then the result of optimal value $\left(\lambda^{*}\right)$ is 0 , that means strong inconsistent [16]. This conclusion is contrary to the definition that increases the fuzzy pairwise comparison matrix, the higher the value, so research needs to be done to calculate whether the resulting value reflects fuzzy inconsistency. There is the difference conclusion between AHP and LFPP method about the consistency. This difference makes us decide to check and ensure that the fuzzy pairwise matrix comparison is truly consistent.

The proposed model was developed by modifying the pairwise matrix comparison steps, using the CFPR method before weighting criteria. By applying the CFPR method, the consistency of the fuzzy preference relationships provided by decision-makers will be improved. The CFPR method answers the weakness of the Analytical Hierarchy Process (AHP) method, which causes the situation to be inconsistent because there are too many questions and comparisons, creating waste and time inefficiency. The CFPR method only requires $n-1$ comparison that must be answered by the evaluator, and the rest is derived using a predetermined proposition formula [24]. Combining the CFPR and LFPP methods are expected to increase the optimal value, not equal 0 (called extended CFPR).

The extended CFPR Model (ECFPR) is a modification of the step comparison of the fuzzy pair matrix using the CFPR method before weighting the criteria. The ECFPR model gives a new proposition, which is formed as Proposition 6.

Proposition 6. Consider set criteria or alternatives, $X=\left\{x_{1}, x_{2}, \ldots, x_{n}\right\}$ associated with a reciprocal multiplicative preference relation $\mathrm{A}=\left(\mathrm{a}_{\mathrm{ij}}\right), \mathrm{a}_{\mathrm{ij}}=\left(\mathrm{l}_{\mathrm{ij}}, \mathrm{m}_{\mathrm{ij}}, \mathrm{u}_{\mathrm{ij}}\right)$, where $\mathrm{a}_{\mathrm{ij}}$ is a member of a triangular fuzzy number. The TFN used to construct fuzzy evaluation matrix on ECFPR method. If the strong importance of element $j$ over element $i$ holds, then the pairwise comparison scale can be represented by the fuzzy number where $0<1_{i j}<m_{i j}<u_{i j}$, for all $i, j=1,2, \ldots, n, j \neq i$. For each $p_{i j}$ where $i=j+1$ or $i=j$, the elements can be transformed as (12). 
$p_{i j}=g\left(l_{i j}, m_{i j}, u_{i j}\right)=\frac{1}{2}\left(1+\log _{9}\left(l_{i j}, m_{i j}, u_{i j}\right)\right)$

Proposition 7. For each $P=\left(p_{i j}\right)=\left(l_{i j}, m_{i j}, u_{i j}\right)$, generally can be written as (13)

$(u, m, l)_{i(i+1)}+(u, m, l)_{(j+1)(i+2)}+\ldots$

$+(u, m, l)_{(i+k-1)(i+k)}+(u, m, l)_{(i+k) i}=\left(\frac{k+1}{2}, \frac{k+1}{2}, \frac{k+1}{2}\right)$,

$\forall i<j$

Experiment 2. In experiment 2, the fuzzy paired comparison matrix of the case criteria for shipping registration selection on economic sub-criteria $(X)$ is a $4 \times 4$ matrix [16], [25]. Therefore, using the CFPR method, the number of comparisons to be used is only $(=4-1)$ pairs. Then a new model is formed as a result of the matrix transformation using the propositions that have been determined in the CFPR method.

The first step, transform $X$ into $P$ to describe the differences between AHP and CFPR method in the determining judgment. The formula will calculate the value of $p_{i j}$.

$$
P=\left(\begin{array}{cccc}
(1,1,1) & \left(\frac{2}{3}, 1, \frac{3}{2}\right) & p_{13} & p_{14} \\
p_{21} & (1,1,1) & \left(\frac{2}{5}, \frac{1}{2}, \frac{2}{3}\right) & p_{24} \\
p_{31} & p_{23} & (1,1,1) & \left(\frac{2}{5}, \frac{1}{2}, \frac{2}{3}\right) \\
p_{41} & p_{42} & p_{43} & (1,1,1)
\end{array}\right)
$$

Matrix $P$ shows that $p_{i j}$ is matrix element entries that are not filled in by experts. The ECFPR method fills in values using proposition 9 and proposition 10 for each and so that the matrix output remains a triangular fuzzy number. The whole calculation is as follows;

$$
\begin{aligned}
p_{11}= & p_{22}=p_{33}=1 / 2\left(1+\log _{9}(1,1,1)=(0.5,0.5,0.5),\right. \\
p_{12}= & 1 / 2\left((1,1,1)+\log _{9}(2 / 3,1,3 / 2)=(0.41,0.5,0.59),\right. \\
p_{23}= & 1 / 2\left((1,1,1)+\log _{9}(2 / 5,1 / 2,2 / 3)=(0.3,0.35,0.41),\right. \\
p_{34}= & 1 / 2\left((1,1,1)+\log _{9}(2 / 5,1 / 2,2 / 3)=(0.3,0.35,0.41),\right. \\
p_{21}= & (1,1,1)-(0.59,0.5,0.41)=(0.41,0.5,0.59), \\
p_{32}= & (1,1,1)-(0.41,0.35,0.3)=(0.59,0.65,0.7), \\
p_{43}= & (1,1,1)-(0.41,0.35,0.3)=(0.59,0.65,0.7), \\
p_{31}= & (1.5,1.5,1.5)-((0.59+0.41),(0.5+0.35), \\
& (0.41+0.3))=(0.5,0.65,0.79), \\
p_{42}= & (1.5,1.5,1.5)-((0.41+0.41),(0.35+0.35), \\
& (0.3+0.3))=(0.9,0.8,0.68), \\
p_{41}= & (2,2,2)-((0.59+0.41+0.41),(0.5+0.35+0.35), \\
& (0.41+0.3+0.3))=(0.59,0.8,0.99), \\
p_{13}= & (1,1,1)-(0.79,0.65,0.5)=(0.21,0.35,0.5),
\end{aligned}
$$

$p_{24}=(1,1,1)-(0.9,0.8,0.68)=(0.1,0.2,0.32)$,

$p_{14}=(1,1,1)-(0.9,0.8,0.59)=(0.1,0.2,0.32)$.

Table I depicts a new matrix of criteria that consists of four criteria. Maple 2016 Software calculated the consistency index using LFPP method.

Consistency index using LFPP method for matrix on Table I can be written as Minimize

$$
J=(1-\lambda)^{2}+M \cdot \sum_{i=1}^{3} \sum_{j=i+1}^{4}\left(\delta_{i j}^{2}+\eta_{i j}^{2}\right)
$$

Subject to

$$
\left\{\begin{array}{l}
x_{1}-x_{2}-\lambda \ln (0.5 / 0.41)+\delta_{12} \geq \ln (0.41), \\
-x_{1}+x_{2}-\lambda \ln (0.59 / 0.5)+\eta_{12} \geq-\ln (0.59), \\
x_{1}-x_{3}-\lambda \ln (0.35 / 0.3)+\delta_{13} \geq \ln (0.3), \\
-x_{1}+x_{3}-\lambda \ln (0.5 / 0.35)+\eta_{13} \geq-\ln (0.5), \\
x_{1}-x_{4}-\lambda \ln (0.2 / 0.01)+\delta_{14} \geq \ln (0.01), \\
-x_{1}+x_{4}-\lambda \ln (0.41 / 0.2)+\eta_{14} \geq-\ln (0.41), \\
x_{2}-x_{3}-\lambda \ln (0.35 / 0.3)+\delta_{23} \geq \ln (0.3), \\
-x_{2}+x_{3}-\lambda \ln (0.41 / 0.35)+\eta_{23} \geq-\ln (0.41), \\
x_{2}-x_{4}-\lambda \ln (0.2 / 0.1)+\delta_{24} \geq \ln (0.1), \\
-x_{2}+x_{4}-\lambda \ln (0.32 / 0.2)+\eta_{24} \geq-\ln (0.32), \\
x_{3}-x_{4}-\lambda \ln (0.35 / 0.3)+\delta_{34} \geq \ln (0.35), \\
-x_{3}+x_{4}-\lambda \ln (0.41 / 0.35)+\eta_{34} \geq-\ln (0.41), \\
\lambda, x_{1}, x_{2}, x_{3}, x_{4}, \delta_{12}, \delta_{13}, \delta_{14}, \delta_{23}, \delta_{24}, \delta_{34} \geq 0, \\
\eta_{12}, \eta_{13}, \eta_{14}, \eta_{23}, \eta_{24}, \eta_{34} \geq 0 .
\end{array}\right.
$$

Define a sufficiently large number for $M=10^{3}$, then the result of optimal value $\left(\lambda^{*}\right)$ is 0.309 . The extended CFPR produce different value of $\left(\lambda^{*}\right)$ from traditional LFPP. Based on Wang and Chin (2011), it was noticed that the $\lambda^{*}$ is 0 . Some of the optimal values produced by the LFPP method are close to 0, while the calculation using the ECFPR method shows a cost of more than 0 . However, further research is needed to see the pattern of $\lambda^{*}$ values from the proposed method. Given an $M=10^{1}$, Table II shows the results of the comparison of the calculation of the optimal solution value in several paired matrix experiments on the appropriate shipping registry problem [16].

In this study, the examination of the consistency ratio (CR) value was done by the AHP method. Table II shows that matrices 10 and matrix 13 were inconsistent, with values of 0.23 and 0.27 , respectively (more than 0.10 ). Line 10 is a paired comparison matrix on the labor quality and availability sub-criteria, while on the 13th line at the level of bureaucracy sub-criteria. So, it can be seen that only used 12 patterns to observed based on [16]. Table II shows that the values for the LFPP method vary from negative 1 to 1 . 
TABLE. I. ECFPR MATRIX

\begin{tabular}{|l|l|l|l|l|}
\hline$C$ & $C_{1}$ & $C_{2}$ & $C_{3}$ & $C_{4}$ \\
\hline$C_{1}$ & $(0.5,0.5,0.5)$ & $(0.41,0.5,0.59)$ & $(0.21,0.35,0.5)$ & $(0.01,0.2,0.41)$ \\
\hline$C_{2}$ & $(0.41,0.5,0.59)$ & $(0.5,0.5,0.5)$ & $(0.3,0.35,0.41)$ & $(0.1,0.2,0.32)$ \\
\hline$C_{3}$ & $(0.5,0.65,0.79)$ & $(0.59,0.65,0.7)$ & $(0.5,0.5,0.5)$ & $(0.3,0.35,0.41)$ \\
\hline$C_{4}$ & $(0.59,0.8,0.99)$ & $(0.68,0.8,0.9)$ & $(0.59,0.65,0.7)$ & $(0.5,0.5,0.5)$ \\
\hline
\end{tabular}

TABLE. II. CONSISTENCY INDEX COMPARISON

\begin{tabular}{|c|c|c|c|c|c|c|c|}
\hline \multirow{2}{*}{ Matrix Number } & \multirow{2}{*}{$\mathrm{CR}$} & \multicolumn{2}{|c|}{$M=10^{1}$} & \multicolumn{2}{|c|}{$M=10^{2}$} & \multicolumn{2}{|c|}{$M=10^{3}$} \\
\hline & & $a$ & $b$ & $a$ & $b$ & $a$ & $b$ \\
\hline 1 & 0.02 & 0.36 & 0.66 & -0.56 & 0.52 & -0.83 & 0.5 \\
\hline 2 & 0.07 & 0.73 & -0.11 & 0.4 & -0.38 & 0.31 & -0.41 \\
\hline 3 & 0.02 & 0.3 & 0.65 & -0.82 & 0.15 & -1.17 & 0.02 \\
\hline 4 & 0.00 & 0.42 & 1 & 0.19 & 1 & 0.16 & 1 \\
\hline 5 & 0.09 & 0.82 & 0.02 & 0.72 & -0.56 & 0.71 & -0.69 \\
\hline 6 & 0.02 & 0.86 & 0.41 & 0.78 & 0.17 & 0.76 & 0.14 \\
\hline 7 & 0.00 & 0.67 & 1 & 0.27 & 1 & 0.16 & 1 \\
\hline 8 & 0.07 & 0.69 & 0.04 & 0.65 & -0.28 & 0.65 & -0.33 \\
\hline 9 & 0.05 & 0.79 & 0 & 0.63 & -0.36 & 0.6 & -0.41 \\
\hline 10 & 0.23 & 0.93 & -1.15 & 0.91 & -2.12 & 0.9 & -2.26 \\
\hline 11 & 0.03 & 0.8 & 0.34 & 0.69 & 0.16 & 0.66 & 0.13 \\
\hline 12 & 0.09 & 0.96 & -0.26 & 0.92 & -1.21 & 0.91 & -1.39 \\
\hline 13 & 0.27 & 1.07 & -0.96 & 1.13 & -5.05 & 1.14 & -6.64 \\
\hline 14 & 0.03 & 0.29 & 0.4 & 0.14 & 0.14 & 0.12 & 0.1 \\
\hline Mean & - & 0.67 & 0.35 & 0.34 & 0.03 & 0.26 & -0.03 \\
\hline
\end{tabular}

(a) Consistency index $\left(\lambda^{*}\right)$ of ECFPR

The results show that there is no guarantee that the optimal value is always positive, depending on the $M$-value used. It can be seen the consistency index when $M=10^{2}$ and $10^{3}$ are still $<0$ in both methods. Whereas the values $M=10^{1}$ in the ECFPR method produce the consistency index between 0.29 to 1 , all are positive and selected for weight calculation. Based on Table II, the ECFPR mean is 0.67 has a higher value than LFPP (0.35). Therefore $M=10^{1}$ can be used to get a higher consistency value.

\section{B. Usability Evaluation Model}

Flowchart of an ECFPR to evaluate e-commerce usability that consists of eight steps (Fig. 1). Determining usability criteria is the first step of evaluation. Developers and usability experts define essential rules in the assessment. The literature study activity often used to collect several papers relating to usability e-commerce, then looks for the right criteria in measurement. After choosing the proper rules, the next is to build a model hierarchy based on the taxonomy specified. The next step is to determine the weight of each measure with the help of experts. Experts will provide the level of importance of each test, using the CFPR.

If the expert judgment is considered to be consistent, the weight of each criterion is calculated using the LFPP method. Each weight is then used to calculate the website usability score, and recommendations based on the calculation results. Each block diagram was explained accompanied by a sample case in the following sub-chapters. (b) Consistency index $\left(\lambda^{*}\right)$ of LFPP

Research conducted by Amerson, et al. [20], the website usability performance can be presented by webpage loading time, average server response time, and webpage size in byte. The quality standard of loading time is less than 30 second, response time is less than 0.5 second, and page size must be less than 64 Kbytes. Pingdom and Bitcatcha can be used to measure these three criteria of usability. Average response time is the estimated response time of user interface when the user sends a request to a server. Webpage loading time is the estimated time required to bring up the website page (updated every month). The total page size is one of the essential criteria to optimize the webpage. It is used to estimate the rendering time of a webpage. The larger the size of the page, the longer the rendering time in most cases.

The hierarchical structure that consists of three levels, where the top level represents the goal and the lowest level has the website under consideration (Fig. 2). The decision maker assesses the importance of the criteria described in level 2, namely loading time $\left(C_{1}\right)$, response time $\left(C_{2}\right)$, and page size $\left(C_{3}\right)$. Five of popular e-commerce websites from Indonesia was selected to assess their usability performance. There are Lazada, Blibli, Shopee, JDid, and Mataharimall.

This research used membership function linguistic scale based on Table III. Table IV shows the fuzzy comparison matrix of expert judgment from Decision-Maker (DM). The DM only requires $n-1 \quad(=3-1)$ comparison rating from three criteria. Loading time is fairly strong important than response time, but equally important than the page size. 


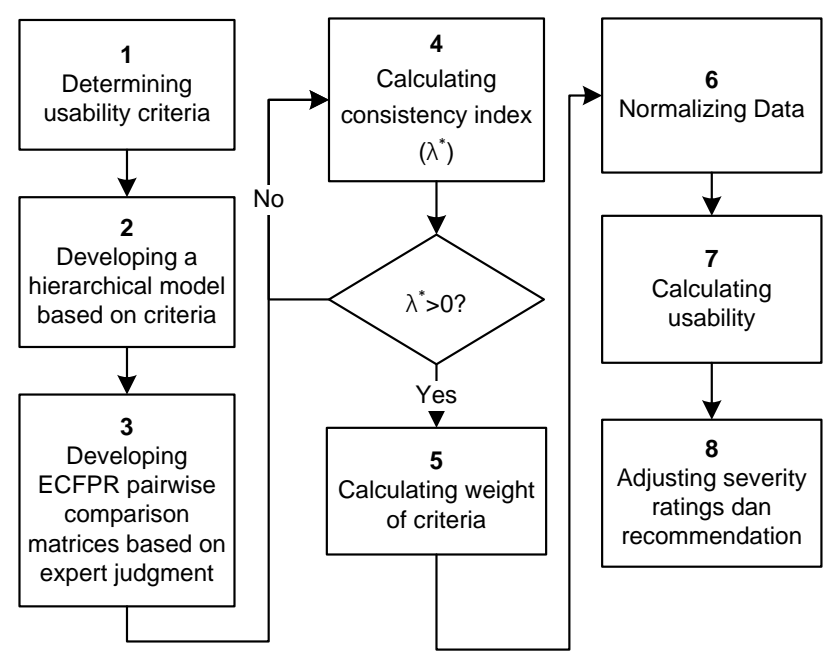

Fig. 1. Usability Evaluation using ECFPR Method.

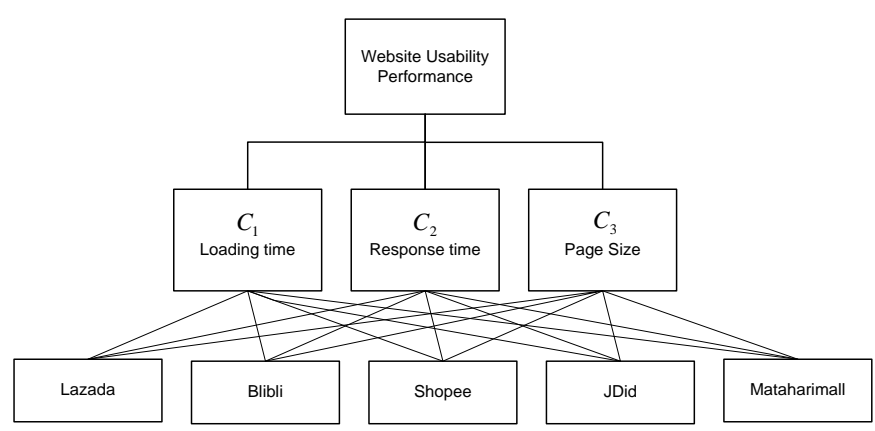

Fig. 2. The Hierarchical Model of Website usability Evaluation.

TABLE. III. MEMBERShiP FunCTION Linguistic SCALE [6]

\begin{tabular}{|l|l|}
\hline Convert from AHP scale to Fuzzy number & Linguistic expressions \\
\hline $1=(1,1,1)$ & Equal \\
\hline $2=(1,2,3)$ & Equal-moderate \\
\hline $3=(2,3,4)$ & Moderate \\
\hline $4=(3,4,5)$ & Moderate-fairly strong \\
\hline $5=(4,5,6)$ & Fairly strong \\
\hline $6=(5,6,7)$ & Fairly strong-very strong \\
\hline $7=(6,7,8)$ & Very strong \\
\hline $8=(7,8,9)$ & Very strong-absolute \\
\hline $9=(8,9,9)$ & Absolute \\
\hline $2,4,6,8$ Values between two adjacent assessments \\
\hline
\end{tabular}

The next step is to fill the section of $p_{i j}$ using ECFPR formula (12) and (13). Table IV represents the matrix transformation result.

TABLE. IV. EXPERT JUDGMENT COMPARISON MATRIX

\begin{tabular}{|l|l|l|l|}
\hline Criteria & $C_{1}$ & $C_{2}$ & $C_{3}$ \\
\hline$C_{1}$ & $(1,1,1)$ & $(4,5,6)$ & $p_{13}$ \\
\hline$C_{2}$ & $p_{21}$ & $(1,1,1)$ & $(1,1,1)$ \\
\hline$C_{3}$ & $p_{31}$ & $p_{32}$ & $(1,1,1)$ \\
\hline
\end{tabular}

$p_{11}=p_{22}=p_{33}=1 / 2\left(1+\log _{9}(1,1,1)=(0.5,0.5,0.5)\right.$,

$p_{12}=1 / 2\left((1,1,1)+\log _{9}(4,5,6)=(0.82,0.87,0.91)\right.$,

$p_{23}=1 / 2\left((1,1,1)+\log _{9}(1,1,1)=(0.5,0.5,0.5)\right.$,

$p_{21}=(1,1,1)-(0.91,0.87,0.82)=(0.09,0.13,0.18)$,

$p_{31}=(1.5,1.5,1.5)-((0.91+0.5),(0.87+0.5),(0.82+0.5))$

$=(0.09,0.13,0.18)$,

Based on Table V, LFPP method (2) used to calculate the consistency index $\left(\lambda^{*}\right)$, can be expressed as Minimize.

$J=(1-\lambda)^{2}+M \sum_{i=1}^{2} \sum_{j=i+1}^{3}\left(\delta_{i j}^{2}+\eta_{i j}^{2}\right)$

Subject to

$\left\{\begin{array}{l}x_{1}-x_{2}-\lambda \ln (0.87 / 0.82)+\delta_{12} \geq \ln (0.82), \\ -x_{1}+x_{2}-\lambda \ln (0.91 / 0.87)+\eta_{12} \geq-\ln (0.91), \\ x_{1}-x_{3}-\lambda \ln (0.87 / 0.82)+\delta_{13} \geq \ln (0.82), \\ -x_{1}+x_{3}-\lambda \ln (0.91 / 0.87)+\eta_{13} \geq-\ln (0.91), \\ x_{2}-x_{3}-\lambda \ln (0.5 / 0.5)+\delta_{23} \geq \ln (0.5), \\ -x_{2}+x_{3}-\lambda \ln (0.5 / 0.5)+\eta_{23} \geq-\ln (0.5), \\ \lambda, x_{1}, x_{2}, x_{3} \geq 0, \\ \delta_{12}, \eta_{12}, \delta_{13}, \eta_{13}, \delta_{23}, \eta_{23} \geq 0 .\end{array}\right.$

Define $M=10^{1}$, the result value of $\lambda^{*}, \delta^{*}, \eta^{*}$, and $x$ can be represented as follows:

$$
\lambda^{*}=0.76, \delta_{12}^{*}=8.16 \times 10^{-10}, \quad \eta_{12}^{*}=0.2229, x_{1}=0.9060,
$$
$\delta_{13}^{*}=0.2229, \quad \eta_{13}^{*}=2.622, x_{2}=0.8118, \delta_{23}^{*}=8.94 \times 10^{-10}$, $\eta_{23}^{*}=0.2229, x_{3}=1.282$. The result shows that the consistency index is 0.76 more than 0 or consistent. Thus the next step can be continued.

The weight derivation based on [16] of each criterion is calculated by (3). So, the weight can be shown as below.

$$
\begin{gathered}
w_{1}^{*}=\exp (0.906) /((\exp (0.906)+\exp (0.811)+\exp (1.282))=0.297, \\
w_{2}^{*}=\exp (0.811) /((\exp (0.906)+\exp (0.811)+\exp (1.282))=0.270, \\
w_{3}^{*}=\exp (1.282) /((\exp (0.906)+\exp (0.811)+\exp (1.282))=0.432 .
\end{gathered}
$$

Thus, it can be seen that the weight of response time is 0.297 , webpage load time is 0.270 , and webpage size is 0.432 .

TABLE. V. ECFPR MATRIX COMPARISON

\begin{tabular}{|l|l|l|l|}
\hline Criteria & $C_{1}$ & $C_{2}$ & $C_{3}$ \\
\hline$C_{1}$ & $(0.5,0.5,0.5)$ & $(0.82,0.87,0.91)$ & $(0.82,0.87,0.91)$ \\
\hline$C_{2}$ & $(0.09,0.13,0.18)$ & $(0.5,0.5,0.5)$ & $(0.5,0.5,0.5)$ \\
\hline$C_{3}$ & $(0.09,0.13,0.18)$ & $(0.5,0.5,0.5)$ & $(0.5,0.5,0.5)$ \\
\hline
\end{tabular}




\section{RESULT AND DISCUSSION}

These five sites were analyzed for one month (4th May to 4th June 2019). Pingdom used for collecting loading time (second) and page size (MB). Response time data collected using Bitcatcha (ms). Table VI shows the original data for five alternatives.

The original data is then normalized using the Linear Weightage Model [6], [26]. Load time, response time and page size are the maximum criteria because the smallest size is the best. Equation (14) used to normalize the original data.

$r_{i j}=\frac{\max -x_{i j}}{\max -\min }$, for maximum threshold,

where $r_{i j}$ is the normalized criteria, max is the maximum value of the particular criteria among all websites, min is minimum value of the same criteria among the whole websites, and $x_{i j}$ is the specific website that is considered at the time.

Table VII shows normalized data and the final result of extended CFPR method on accessing the usability of ecommerce websites. Equation (15) used to calculate usability score, where $l$ is the number of alternatives, $n$ is the number of criteria, $r_{i j}$ is normalized value, and $w_{j}$ is the weight of criteria.

usability score $=\sum_{i=1}^{l} \sum_{j=1}^{n} w_{j} \times r_{i j} ; i=1,2, \ldots, l, j=1,2, \ldots, n$

Mataharimall has the highest usability score (0.62), and Blibli has the lowest $(0.27)$. The usability score can then be used as a reference recommendation to the developers. Blibli has a high loading time, but the response time is low. Therefore speed factor needs to be considered when it comes to website design improvements. The value of severity ratings also calculated so that the developers can know the extent of the level of seriousness of the website [27]. Severity rating assigned on a 4 -point scale $(1=$ irritant, $2=$ moderate, $3=$ severe, 4 = unusable). Next, presentage of severity was assigned also on a 4 -point scale $(1=$ less than 10 percent ; $2=$ 11 to 50 percent; $3=51$ to 89 percent ; $4=$ more than 90 percent). Severity rating can be measured as (100\%-(usability scores*100)). The best-ranking law in the ECFPR method is Mataharimall > Shopee > JDid > Lazada > Blibli. Mataharimall and Shopee have a moderate category. Lazada, Blibli, and Jdid have a severity value between 11-50\% (severe type).

TABLE. VI. ORIGINAL DATA

\begin{tabular}{|l|l|l|l|l|l|}
\hline Criteria & Lazada & Blibli & Shopee & JDid & Mataharimall \\
\hline$C_{1}$ & 6.6 & 1.23 & 0.756 & 4.46 & 3.46 \\
\hline$C_{2}$ & 256.875 & 543 & 258.625 & 371.5 & 365 \\
\hline$C_{3}$ & 4.9 & 1.9 & 2.4 & 1.9 & 0.142578 \\
\hline
\end{tabular}

TABLE. VII. NORMALIZED DATA

\begin{tabular}{|l|l|l|l|l|l|l|}
\hline Criteria & Lazada & Blibli & Shopee & JDid & $\begin{array}{l}\text { Matahari } \\
\text { mall }\end{array}$ & Weight \\
\hline$C_{1}$ & 0.00 & 0.92 & 1.00 & 0.37 & 0.54 & 0.297 \\
\hline$C_{2}$ & 1.00 & 0.00 & 0.99 & 0.60 & 0.62 & 0.27 \\
\hline$C_{3}$ & 0.00 & 0.63 & 0.53 & 0.63 & 1.00 & 0.432 \\
\hline $\begin{array}{l}\text { Usability } \\
\text { Score }\end{array}$ & 0.30 & 0.27 & 0.52 & 0.45 & 0.62 & - \\
\hline $\begin{array}{l}\text { Severity } \\
\text { Rating }\end{array}$ & 70.3 & 72.76 & 47.78 & 54.96 & 38.32 & - \\
\hline Category & severe & severe & moderate & severe & moderate & - \\
\hline
\end{tabular}

\section{CONCLUSION}

E-Commerce website usability can be evaluated from some criteria such as load time, response time, and page size. The usability evaluation framework was constructed using ECFPR to develop the fuzzy pairwise comparison matrix. This framework also used to determine the proper method of evaluating website usability performance. The numerical experiment showed that the consistency index obtained by ECFPR method was more significantly better than LFPP method. It was revealed that the optimal value always more than 0. The ECFPR method was also successfully implemented with the experimental case to evaluate the usability of five ecommerce website in Indonesia. For further study, criteria, and alternatives to testing whether the method works well can be added.

\section{ACKNOWLEDGMENT}

We thank specially to Mr. Handaru Jati, Ph.D from Universitas Negeri Yogyakarta Indonesia who gives the expert judgment about usability criteria and Mr. Ridwan Pandiya, our colleagues from Institut Teknologi Telkom Purwokerto Indonesia who provided insight and expertise that greatly assisted the research.

\section{REFERENCES}

[1] H. R. Hartson, T. S. T. Andre, dan R. R. C. Williges, "Criteria for evaluating usability evaluation methods,” Int. J. Hum. Comput. Interact., vol. 13, no. 4, hal. 1-35, 2001.

[2] R. Y. Naswir, "Towards a Conceptual Model to Evaluate Usability of Digital Government Services in Malaysia," Int. J. Adv. Comput. Sci. Appl., vol. 10, no. 4, hal. 313-322, 2019.

[3] J. S. Challa, A. Paul, Y. Dada, V. Nerella, dan P. R. Srivastava, "Quantification of Software Quality Parameters Using Fuzzy Multi Criteria Approach," in International Conference on Process Automation, Control and Computing, 2011, hal. 1-6.

[4] S. K. Dubey dan A. Mittal, "Measurement of Object Oriented Software Usability using Fuzzy AHP," Int. J. Comput. Sci. Telecommun., vol. 3, no. 5, hal. 98-103, 2012.

[5] S. K. Dubey dan S. Pandey, "Measurement of Usability of Office Application Using a Fuzzy Multi-Criteria Technique," Int. J. Inf. Technol. Comput. Sci., vol. 7, no. 4, hal. 64-72, 2015. 
[6] P. D. D. Dominic dan H. Jati, "A comparison of Asian airlines websites quality: using a non-parametric test," Int. J. Bus. Innov. Res., vol. 5, no. $5,2011$.

[7] I. Masudin dan T. E. Saputro, "Evaluation of B2C website based on the usability factors by using fuzzy AHP \& hierarchical fuzzy TOPSIS," in IOP Conference Series: Materials Science and Engineering, 2016, vol. 114, hal. 1-8.

[8] S. Aydin dan C. Kahraman, "Evaluation of E-commerce website quality using fuzzy multi-criteria decision making approach," IAENG Int. J. Comput. Sci., vol. 39, no. 1, hal. 64-70, 2012.

[9] N. Sehra, Sumeet Kaur Brar, Yadwinder Singh Kaur, "Applications of Multi-criteria Decision Making in Software Engineering," Int. J. Adv. Comput. Sci. Appl., vol. 7, no. 7, 2016.

[10] L.-X. Wang, "A Course in Fuzzy Systems and Control." Prentice Hall, Hongkong, hal. 1-441, 1997.

[11] R. Wardoyo dan T. Wahyuningrum, "University Website Quality Ranking Using Logarithmic Fuzzy Preference Programming," Int. J. Electr. Comput. Eng., vol. 8, no. 5, hal. 3349-3358, 2018.

[12] L. Mikhailov, "A fuzzy programming method for deriving priorities in the analytic hierarchy process," J. Oper. Res. Soc, vol. 51, hal. 341-349, 2000.

[13] L. Mikhailov, "A fuzzy approach to deriving priorities from interval pairwise comparison judgements," Eur. J. Oper. Res., vol. 159, no. 3, hal. 687-704, 2004.

[14] E. Iryanti dan R. Pandiya, "Application of Logarithmic Fuzzy Preference Programming for Determining Priority as An Institutional Development Strategy," in International Conference on Computer Applications and Information Processing Technology (CAIPT), 2017, hal. 1-5.

[15] Y. M. Wang dan K. S. Chin, "A linear goal programming priority method for fuzzy analytic hierarchy process and its applications in new product screening," Int. J. Approx. Reason., vol. 49, no. 2, hal. 451-465, 2008.

[16] Y. M. Wang dan K. S. Chin, "Fuzzy analytic hierarchy process: A logarithmic fuzzy preference programming methodology," Int. J. Approx. Reason., vol. 52, no. 4, hal. 541-553, 2011.
[17] S. Dožić, T. Lutovac, dan M. Kalić, "Fuzzy AHP approach to passenger aircraft type selection," J. Air Transp. Manag., vol. 68, 2017.

[18] M. Balouchi dan E. Khanmohammadi, "Using logarithmic fuzzy preference programming to prioritization social media utilization based on tourists' perspective," Found. Manag., vol. 7, no. 1, hal. 7-18, 2015.

[19] M. Momeni, A. Sasani, M. R. Fathi, dan E. Khanmohammadi, "Applying Logarithmic Fuzzy Preference Programming for Ranking of Effective Organizational Factors on Creativity: A Case Study Mansour Momeni Faculty of Management University of Tehran," Int. J. Bus. Soc. Sci., vol. 3, no. 14, hal. 83-95, 2012.

[20] E. Herrera-Viedma, F. Herrera, F. Chiclana, dan M. Luque, "Some issues on consistency of fuzzy preference relations," Eur. J. Oper. Res., vol. 154, no. 1, hal. 98-109, 2004.

[21] T. L. Saaty, "How to make a decision: The Analytical Hierarchy Process," Eur. J. Oper. Res., vol. 48, hal. 9-26, 1990.

[22] R. W. Saaty, "The analytic hierarchy process-what it is and how it is used," Math. Model., vol. 9, no. 3-5, hal. 161-176, 1987.

[23] H. Khademi-Zare, M. Zarei, A. Sadeghieh, dan M. Saleh Owlia, "Ranking the strategic actions of Iran mobile cellular telecommunication using two models of fuzzy QFD," Telecomm. Policy, vol. 34, no. 11, hal. 747-759, 2010

[24] R. J. Chao dan Y. H. Chen, "Evaluation of the criteria and effectiveness of distance e-learning with consistent fuzzy preference relations," Expert Syst. Appl., vol. 36, no. 7, hal. 10657-10662, 2009.

[25] M. Celik, I. D. Er, dan A. F. Ozok, "Application of fuzzy extended AHP methodology on shipping registry selection: The case of Turkish maritime industry," Expert Syst. Appl., vol. 36, no. 1, hal. 190-198, 2009.

[26] A. A. Ali dan P. D. D. Dominic, "A Case Study of Linear Weightage Model for Supplier Selection Process," 2008 Int. Symp. Inf. Technol., vol. 3, hal. 23-26, 2008.

[27] T. Tullis dan B. Albert, Measuring The User Experience. USA: Morgan Kaufmann, 2013. 